EESTI NSV TEADUSTE AKADEEMIA TOIMETISED 1955. IV kd., nr. 1 ИЗВЕСТИЯ АКАДЕМИИ НАУК ЭСТОНСКОИ ССР 1955, Том IV, № 1

\title{
ОКИСЛИТЕЛЬНАЯ ДЕСТРУКЦИЯ КЕРОГЕНА КУКЕРСИТА *
}

\author{
А. С. ФОМИНА, \\ кандидат технических наук
}

\section{л. я. поБуль}

Как указывалось в первом сообщении $\left({ }^{3}\right)$, при окислительной деструкции керогена кукерских сланцев перманганатом калия наряду с одноосновными легучими с водяным паром кислотами, нелетучей щавелевой кислотой и гетероатомными кислотами сложного состава получаются двухосновные насыщенные кислоты выше щавелевой. При частичном окислении (деструктируется около $50 \%$ углерода керогена) на углерод керогена в целом получается $10-11 \%$ двухосновных кислот выше щавелевой. При индивидуализации этих кислот методом фракционной кристаллизации в смеси были установлены_ледующие кислоты: янтарная, глутаровая, адипиновая, пимелиновая, пробковая и азелаиновая. Разделение такой сравнительно сложной смеси на индивидуальные соединения методом фракционной кристаллизации как по сырью, так и трудоемкости не обеспечивало стоявших перед исследователями задач. Применение распределительной хроматографии для разделения и идентификации летучих с водяным паром жирных кислот показало пригодность этого метода как для качественного, так и для количественного анализа смеси исследуемых кислот $\left({ }^{4}\right)$, поэтому и для индивидуализации двухосновных кислот было решено использовать распределительную хроматографию на силикагелевых колонках. За основу был принят метод, описанный Хигучи, Хиллом и Коркорен $\left({ }^{8}\right)$. Двухосновные кислоты, до пимелиновой, упомянутые авторы разделяют на силикагелевых колонках с применением воды в качестве буфера. Кислоты от пимелиновой и выше разделяют с применением в качестве буфера $1 M$ водного раствора лимоннокислого натрия с $\mathrm{pH}=5,2$. В качестве подвижных растворителей применяют растворенный в хлороформе $н$-бутиловый спирт различной концентрации. Растворение исследуемой смеси кислот, во избежание процесса этерификации, производят в растворе третичного амилового спирта в хлороформе. Опробование этого метода показало его пригодность для исследуемой смеси и поэтому с небольшими изменениями он был использован нами для разделения.

* Сообщение третье. (Выделение и идентификация насыщенных двухосновных кислот.) 


\section{1. Описание эксперимента и полученных результатов}

Приготовление силикагелевой колонки. Силикагель изготовлялся из продажного жидкого стекла по Ишервуду $\left({ }^{7}\right)$. Для получения первичных хроматограмм употреблялась малая колонка высотой 250 мм и диаметром 12 мм. Загрузка силикагеля составляла 25 г. Силикагель лабораторного приготовления имел активность 15-17. Силикагель измельчался до полного прохождения через сито № 100 и затем в фарфоровой чашке, при тщательном перемешивании смачивался буферным раствором. В первой колонке буферным раствором служила вода, во второй колонке - $1 M$ водный раствор лимоннокислого натрия с $\mathrm{pH}=5,2$. Большое значение имеет количество буферного раствора и тщательность увлажнения им силикагеля. Обработанный буферным раствором силикагель не должен быть очень мокрым, но в то же время не должно оставаться и неувлажненных крупинок силикагеля. Недостаток или излишек буферного раствора выявляется в процессе укладки колонки.

Для заполнения колонки увлажненный буферным раствором силикагель смешивается с дихлорэтаном (или хлороформом) в отношении от $1: 10$ до 1: 15. В том случае, когда операция смачивания буферным раствором проведена хорошо, силикагель в дихлорэтане дает хорошую равномерную взвесь; если же силикагель не был весь увлажнен буферным раствором, то взвесь силикагеля получается разнородной, с белыми, несмоченными крупинками. В последнем случае силикагель будет плохо укладываться в колонке и сама колонка будет медленно работать и неудовлетворительно разделять. Если буферный раствор был дан в избытке, то при укладке колонки не удается достигнуть необходимой плотности и колонка будет работать слишком быстро, что тоже приводит к неудовлетворительным результатам. Қак показал опыт работы, количество буферного раствора должно быть подобрано экспериментально, в зависимости от активности носителя. Для более активных силикагелей буферного раствора требуется больше, чем для менее активных.

При укладке колонки вышеуказанная взвесь силикагеля в дихлорэтане частями заливается в колонку. Каждая следующая порция дается тогда, когда над слоем силикагеля еще имеется дихлорэтан. После введения в колонку всей взвеси, не давая стечь всему дихлорэтану, в колонку вводят стеклянный поршень, которым утрамбовывают силикагель до состояния скорости вытекания дихлорэтана $40-50$ мл в час, после чего колонка готова для анализа. Поршень извлекается, и поверхность силикагеля предохраняется слоем дихлорэтана. Если к анализу приступают сразу, то навеска смеси кислот в растворе третичного бутилового или амилового спирта в дихлорэтане вводится в колонку как только над силикагелем останется слой дихлорэтана в $2-3$ мм. Когда залитый по стенке исследуемый раствор пройдет колонку (над поверхностью останется также слой дихлорэтана в 2-3 мм), по стенке осторожно вводят первый вымывающий растворитель и в таком же порядке вводятся растворители последующих концентраций. Для получения первичных хроматограмм мы брали 0,06 г смеси в виде $1 \%$ раствора кислот в $10 \%$ растворе третичного бутилового спирта в дихлорэтане. При указанной выше активности силикагеля для увлажнения 25 г его требовалось 15 мл дестиллированной воды в качестве буфера. Элюаты собирались по 5 или 10 мл и титровались в присутствии фенолфталеина $0,025 \mathrm{~N}$ спиртовой щелочью. Концентрации отдельных подвижных растворителей будут указаны ниже.

Х роматографи ров ание исследуемой смеси кислот. При разделении продуктов окислительной деструкции керогена на отдельные группы кислых продуктов двухосновные кислоты выше щавеле- 
вой были получены в виде трех фракций, две из которых были кристаллические и одна вязкая. После отделения летучих с водяным паром кислот, щавелевой кислоты и гетероатомных кислот сложного состава подкисленный водный раствор подвергался далее жидкость-жидкостной экстракции этиловым эфиром (с трехкратным последовательным упариванием и экстракцией). После отгонки из экстракта растворителя были получены вязкие кислоты, из которых при стоянии выделилось значительное количество кристаллических кислот. Кристаллы были отделены от вязкой части фильтрованием. Водный раствор после экстрагирования эфиром частично нейтрализовался и выпаривался досуха. Сухой остаток снова экстрагировался эфиром. После удаления растворителя из экстракта были получены кристаллические кислоты. Для получения первичных хроматограмм все указанные выше фракции были подвергнуты раздельному хро-

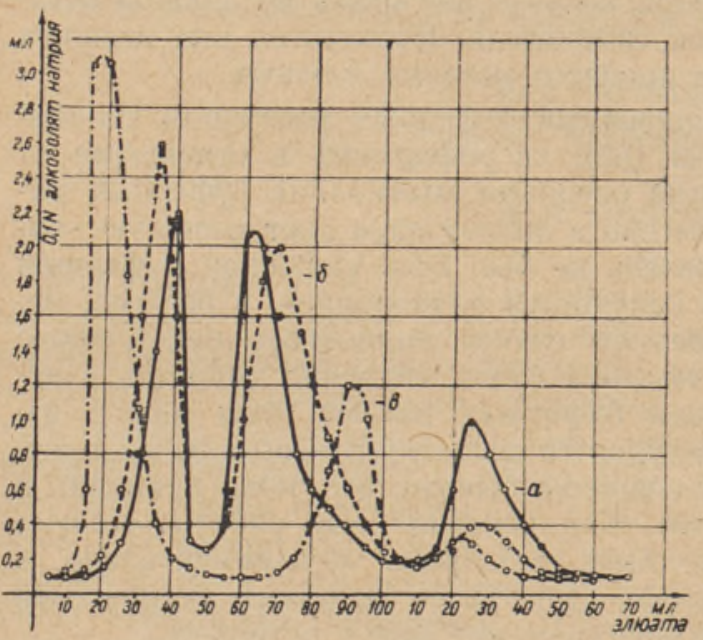

Рис. 1. Хроматографическое разделение на снликагелевой колонке двухосновных насыщенных кислот от $\mathrm{C}_{4}$ до $\mathrm{C}_{7}$ (буферный раствор - дестиллированная вода).

матографированию. Выходные кривые этих хроматографирований приведены на рис. 1. Кривая $a$ относится к кристаллам, выделенным совместно с вязкими кислотами при жидкостной экстракции, кривая б-к кристаллам, полученным из сухого остатка, и кривая $в-\mathrm{K}$ вязкой фракции кислот.

Из выходных кривых $a$ и $\sigma$ видно, что кристаллические фракции являются смесями одних и тех же кислот. Некоторое смещение областей выхода кислот, очевидно, обусловливалось различными соотношениями кислот в смесях. Кривая 8 резко отличается от кривых $a$ и б, указывая тем самым на отличие состава вязких кислот от составляющих смеси кристаллических кислот.

Для накопления индивндуальных кислот 20 г кристаллических и 20 г вязких кислот были разделены на большой/ колонке высотой 700 мм и диаметром 30 мм, при загрузке 60 г силикагеля. Количество необходимого буферного раствора составляло 40 мл (дестиллированная вода). Кристаллические кислоты вымывались растворами н-бутилового спирта в дихлорэтане в следующих концентрациях: первая фракция - 5\%, вторая $10 \%$ и третья - 35\%. При разделении на большой колонке отбирались три главные фракции и промежуточные фракции (по 20-30 мл), соответствующие областям минимумов. Из промежуточных фракций кислоты не выделялись. При разделении вязких кислот первая фракция вымывалась $5 \%$ и вторая $20 \%$ раствором н-бутилового спирта в дихлорэтане. Навеска смеси кислот для одного опыта составляла 0,5 г. Первые фракции элюатов представляли смесь высших гомологов и подлежали дальнейшему разделению на колонках с буферным раствором $1 M$ лимоннокислого натрия. Последующие элюаты содержали индивидуальные соединения и из них, после отгонки растворителя, были получены отдельные кислоты. 
Для разделения на второй колонке первые фракции кристаллических и вязких кислот были соединены для совместного хроматографирования. Первичное хроматографирование было сразу произведено на большой колонке (60 г силикагеля и 40 мл $1 M$ раствора лимоннокислого натрия). Навеска смеси кислот в количестве 0,5 г готовилась в виде $1 \%$ раствора в $5 \%$ третичном бутиловом спирте в дихлорэтане (50 мл). Вымывание отдельных кислот пронзводилось последовательно 3, 10, 20 и 35\% раствором $н$-бутилового спирта в дихлорэтане. Выходная кривая этого хроматографирования приведена на рис. 2.

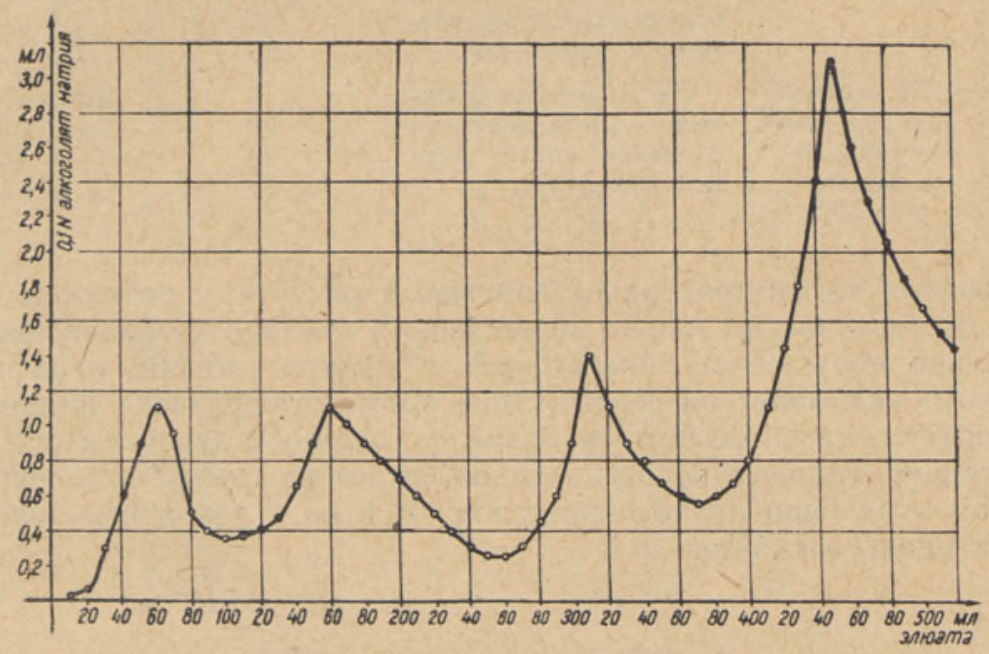

Рис. 2. Хроматографическое разделение на силикагелевой колонке двухосновных кислот от $C_{7}$ и выше (буферный раствор - $1 M$ лимоннокислый натрий с $\mathrm{pH}=5,2)$.

Как видно из первичной хроматограммы, в смеси содержится по меньшей мере четыре кислоты. Область максимумов четко отделяется, однако через всю хроматограмму проходит как бы полоса, маскирующая четкость разделения отдельных соединений в области минимумов. Все же разделение на четыре фракции было произведено. После отгонки растворителя были получены вязкие фракции, но при непродолжительном стоянии из II, III и IV фракций начали выделяться кристаллы, которые затем составили главную массу этих фракций. Первая фракция даже при длительном стоянии не выделяла кристаллов. Кристаллы II, III и IV фракций были отделены от вязкой части фильтрованием. После отделения вязких кислот от кристаллических, первые потеряли способность растворяться в воде. Поскольку исследование вязких кислот не входило в задачу настоящего этапа работы, дальнейшее обследование их не производилось. Весь цикл хроматографического разделения двухосновных кислот приведен в таблице 1.

С целью идентификации полученные при хроматографировании индивидуальные кислоты были перекристаллизованы из наибольших количеств $5 \%$ раствора $н$-бутилового спирта в дихлорэтане. Затем были определены температуры плавления их и элементарный состав. Кроме того, для каждой кислоты были приготовлены дианилиды, которые, в свою очередь, были охарактеризованы по температурам плавления и элементарному составу. Әкспериментально полученные данные для всех выделенных двухосновных кислот, температуры плавления для чистых кислот и их дианн- 
Разделение двухосновных насыщенных кислот частичного окисления керогена кукерских сланцев (от $\mathrm{C}_{4}$ до $\mathrm{C}_{9}$ включительно)

\begin{tabular}{|c|c|c|c|c|}
\hline $\begin{array}{c}\text { № } \\
\text { колонки }\end{array}$ & $\begin{array}{l}\text { Буферный } \\
\text { раствор }\end{array}$ & $\begin{array}{c}\text { Исследуемая смесь } \\
\text { кислот }\end{array}$ & $\begin{array}{c}\text { Подвижный } \\
\text { растворитель } \\
\text { в \% н-бутило- } \\
\text { вого спирта }\end{array}$ & $\begin{array}{c}\text { Выделяемые } \\
\text { кислоты }\end{array}$ \\
\hline I & Вода & $\begin{array}{l}\text { Смесь кристалличе- } \\
\text { ских и вязких кислот, } \\
\text { полученных при час- } \\
\text { тичном окислении }\end{array}$ & $\begin{array}{r}5 \\
10 \\
20 \\
35\end{array}$ & $\begin{array}{l}\mathrm{C}_{7} \text { и выше } \\
\mathrm{C}_{6} \\
\mathrm{C}_{5} \\
\mathrm{C}_{4}\end{array}$ \\
\hline II & $\begin{array}{c}1 \text { М водный } \\
\text { раствор ли- } \\
\text { моннокисло- } \\
\text { го натрия с } \\
\text { рН }=5,2\end{array}$ & $\begin{array}{l}\text { Смесь первых фрак- } \\
\text { ций кристаллических } \\
\text { и вязких кислот пер- } \\
\text { вой колонки }\end{array}$ & $\begin{array}{r}3 \\
10 \\
20 \\
35\end{array}$ & 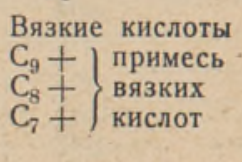 \\
\hline
\end{tabular}

лидов, взятые по литературным данным, и расчетные величины элементарного состава чистых кислот приведены в таблице 2. Сравнение экспериментально полученных показателей с литературными и расчетными величинами указывает на соответствие хроматографически индивидуализированных соединений двухосновным насыщенным кислотам от $\mathrm{C}_{4}$ до $\mathrm{C}_{9}$ включительно. Количественные выходы кислот на сумму выделенных при частичном окислении двухосновных кислот и на углерод исходного керогена приведены в таблице 3.

\section{2. Обсуждение результатов}

Из данных таблицы 3 следует, что количество двухосновных кислот выше щавелевой (от $\mathrm{C}_{4}$ до $\mathrm{C}_{10}$ ) при деструкции $50 \%$ углерода керогена составляет $9,28 \%$ от всего углерода органического вещества. Учитывая, что имели место неизбежные потери, выход кислот без особой погрешности можно округлить до $10 \%$. Таким образом, даже при частичном окислении выход каждой из приведенных выше кислот составляет ощутимую величину - не менее $1 \%$ на углерод керогена, а выход кислоты с длиной углеродніо̆ цепи 5 и 6 атомов - 2 и $2,5 \%$. Следовательно, уже по данным частичного окисления можно полагать, что исходные (материнские) вещества этих кислот играют существенную роль в строении вещества керогена. Если же проанализировать потенциальный выход этих кислот, а следовательно, и потенциальное содержание в керогене исходных соединений, из которых они образуются при окислительной деструкции, то получается следующая картина: при деструкции половины углерода $(47 \%)$ выход кислот от $\mathrm{C}_{4}$ по $\mathrm{C}_{9}$ составляет $10 \%$, следовательно при соответствующей деструкции всего керогена их выход составит удвоенное количество. Основанием для этого заключения является поведение керогена при окислительной деструкции в условиях данного эксперимента $\left({ }^{3}\right)$.

Не вызывает сомнения и то положение, что в условиях окислительной деструкции перманганатом калия часть двухосновных кислот подвергается последующей деструкции вплоть до щавелевой кислоты и даже двуокиси углерода. Әто снижает действительный выход их от углерода керогена и дает основание полагать, что известная доля или даже вся щавелевая кислота получается в результате окисления этих кислот. Основанием для подобного заключения являются результаты настоящего исследования $\left({ }^{3}\right)$ и анализ данных, полученных другими исследователя- 


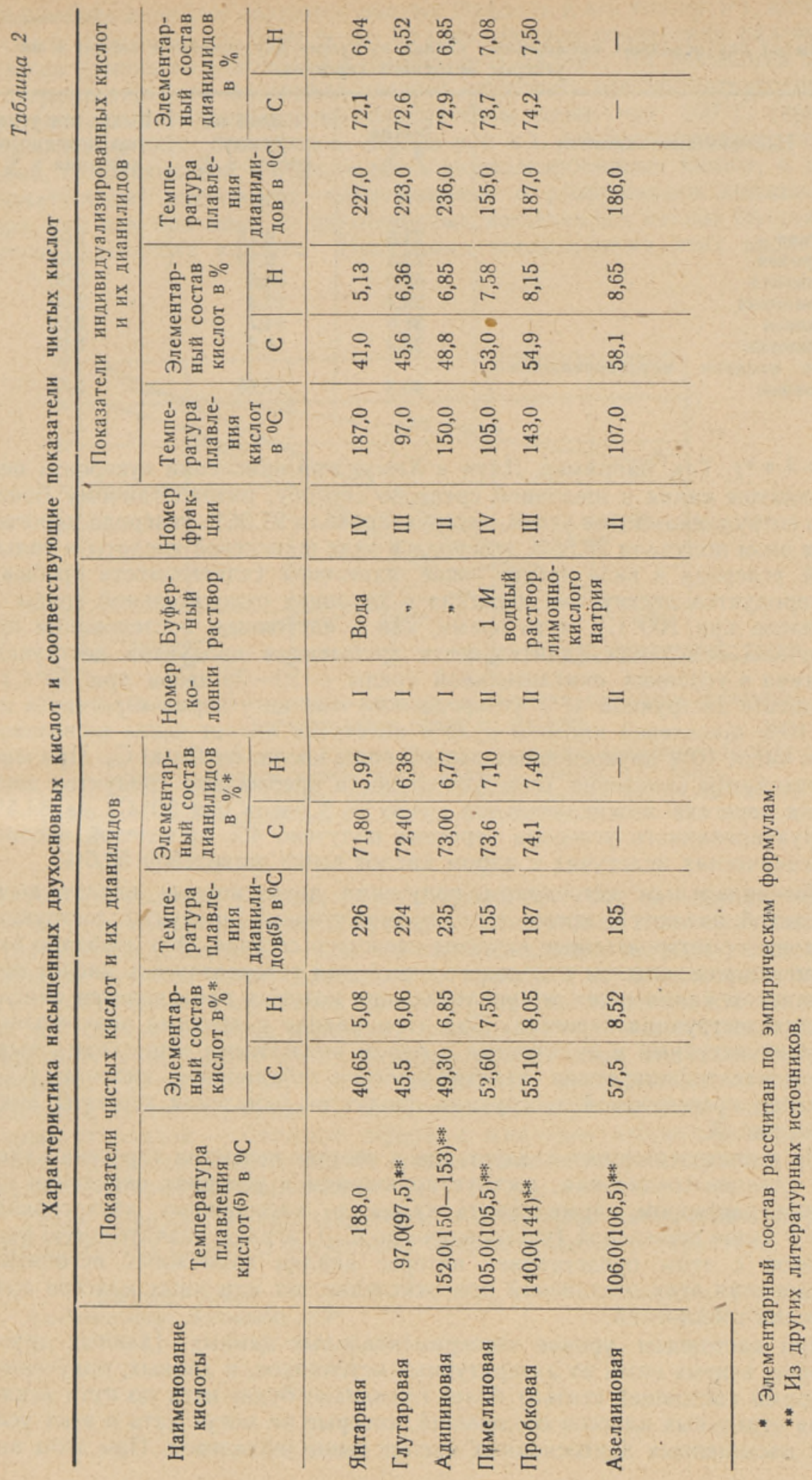




\begin{tabular}{l|c|c|c}
\hline \multicolumn{1}{c|}{ Наименование кислоты } & $\begin{array}{c}\text { Выход } \\
\text { в \% }\end{array}$ & $\begin{array}{c}\text { Выход на } \\
\text { сумму } \\
\text { кислот в \% }\end{array}$ & $\begin{array}{c}\text { Выход на угле- } \\
\text { род исходного } \\
\text { керогена в \% }\end{array}$ \\
\hline & & & \\
Янтарная & 23,6 & 9,15 & 1,01 \\
Глутаровая & 23,5 & 9,12 & 1,01 \\
Адипиновая & 48,0 & 18,6 & 2,06 \\
Пимелиновая & 59,2 & 22,9 & 1,62 \\
Пробковая & 38,0 & 14,7 & 1,08 \\
Азелаиновая & 25,3 & 9,8 & 1,74 \\
Вязкие кислоты \\
\multicolumn{1}{c|}{ строения }
\end{tabular}

ми $(1,2,6,9)$. Так, например, Даун и Химус при окислении кукерсита перманганатом калия в щелочной среде по способу, разработанному Боном и его сотрудниками для углей, деструктировали $91,06 \%$ углерода керогена и при этом получили $28,55 \%$ углерода в виде щавелевой кислоты и только $3,82 \%$ углерода в виде кислот выше щавелевой (длительность пребывания продуктов деструкции керогена в условиях окислительной среды 115 часов при $\left.100^{\circ} \mathrm{C}\right)$, в то время, как в настоящем исследовании при частичном окислении (длительность пребывания продуктов деструкции керогена в условиях окислительной среды $-20-28$ часов при $50^{\circ} \mathrm{C}$ ) в результате деструкции $47 \%$ углерода получено на углерод керогена в целом $10 \%$ щавелевой кислоты и $22 \%$ нелетучих кислот выше щавелевой, в том числе $10 \%$ двухосновных насыщенных кислот от $\mathrm{C}_{4}$ по $\mathrm{C}_{9}$. При многоступенчатом окислении (при длительности пребывания продуктов деструкции керогена в окислительной среде до 3 часов при $50^{\circ} \mathrm{C}$ ) на $84,5 \%$ деструктированного углерода керогена получено 4\% щавелевой кислоты и органических нелетучих с паром кислот выше щавелевой 59,6\%.

Потенциальным источником получения двухосновных кислот выше щавелевой являются, кроме того, промежуточные продукты деструкции керогена - гетероатомные кислоты сложного состава. Это доказано экспериментально, опытом отдельного окисления гетероатомных кислот перманганатом калия в тех же условиях, при которых производится окислительная деструкция керогена. При этом наряду с другими низкомолекулярными летучими и нелетучими с паром кислотными веществами выделена и идентифицирована кристаллическая себациновая кислота $\left(\mathrm{C}_{10}\right)$. Характер последующей деструкции продуктов окисления керогена показан на рис. 3.

Из вышеизложенного следует, что в составе вещества керогена кукерских сланцев соединения, деструктирующиеся в условиях окисления щелочным раствором перманганата калия до насыщенных двухосновных кислот выше щавелевой (установлено до $\mathrm{C}_{10}$ ), играют значительную роль. В связи с этим представляет интерес анализ возможных источников образования этих соединений при окислении тех или иных классов органических соединений.

При настоящем уровне экспериментальных данных (данных других авторов, взятых нами из литературных источников, и данных, полученных авторами настоящей статьи) более правильно будет итти по пути исключения отдельных классов соединений, которые не могут дать в этих условиях насыщенных двухосновных кислот выше щавелевой. При этом ана- 
лизе весьма ценными являются данные Рандола и его коллег $\left({ }^{9}\right)$, которые провели окисление по Бону более 60 органических соединений различных классов (кипящим раствором перманганата калия). На основании этого экспериментального материала следует исключить все ароматические соединения, не окисляемые этим окислителем даже при $100^{\circ} \mathrm{C}$ (хризен, ретен, декациклен, бензофенон, бензил и т. п.), все ароматические соединения, окисляющиеся с образованием бензолкарбоновых кислот, и даже ароматические соединения, окисляющиеся с разрушением бензольного ядра, так как при этом из двухосновных насыщенных кислот получается только щавелевая кислота. Исходными соединениями этих кислот не

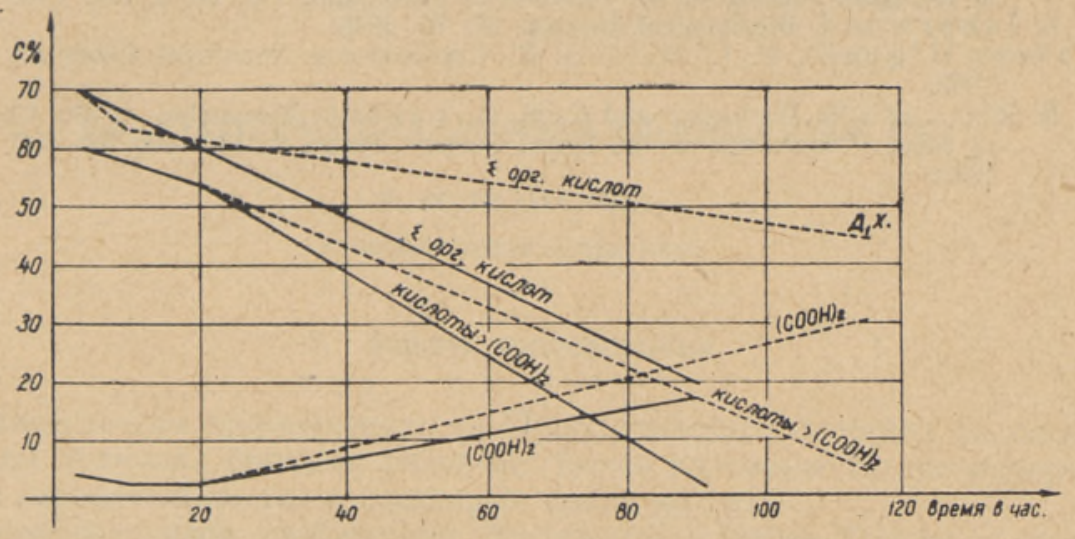

Рис. 3. Окисление продуктов деструкции керогена кукерсита щелочным перманганатом калия во времени.

. . . . . . данные Дауна и Химуса. Выходы продуктов при окислении кипящим раствором перманганата калия в течение 115 часов.

- данные авторов настоящей статьи. Выходы продуктов окисления при $50^{\circ}$; время пребывания в окнслительной среде $3,8,20-28$ и 90 часов.

могут быть полиозы (крахмал, целлюлоза и др.), так как при их окислении из двухосновных кислот получается также только щавелевая кислота. Отпадает также лигнин - при его окислении тоже не образуются двухосновные кислоты выше щавелевой и наряду с алифатическими кислотами обязательно получаются бензолкарбоновые кислоты, что не имеет места в случае керогена кукерских сланцев. Исходными веществами для получения этих кислот могли служить производные нафтенового ряда, полимеры $\omega$-оксикислот, альдегидокислот, двухатомных первичных спиртов и другие подобные им производные алифатического ряда, производные стерондов - сложные эфиры с жирными кислотами и простые эфиры с насыщенными спиртами, производные некоторых терпенов и тому подобные природные вещества.

Таким образом, можно заключить, что бо́льшая часть вещества керогена кукерских сланцев, безусловно, неароматического характера.

Институт химии

Академии наук Әстонской ССР
Поступила в редакцию

7 VII 1954 


\section{ЛИТЕРАТУРА}

1. П. К. Когерм ан, Окисление сланцев как метод исследования химической природы керогена, Изв. АН ЭССР, т. I, № 1, 1952.

2. В. А. Л анин и М. В. Прон ина, Об органическом веществе горючих сланцев, Изв. АН СССР, ОТН, № 10-11, 1944.

3. А. С. Фомин а и Л. Я. Побуль, Окислительная деструкция керогена кукерсита, Сообщение первое, Изв. АН ЭССР, т. ІІ, № 1, 1953.

4. А. С. Фомин а и Л. Я. Побуль, Окнслительная деструкция керогена кукерсита, Сообщение второе, Изв. АН ЭССР, т. II, № 4, 1953.

5. Р. Ш $\mathrm{p}$ a й не р и Р. $Ф$ ьюс он, Систематический качественный анализ органических соединений, ИЛ, 1950.

6. A. L. Down and G. W. H i mus, A Preliminary Study of the Chemical Constitution of Kerogen, Journal of the Institute of Petroleum, Vol. 27, p. 426, 1941.

7. F. A. I s he r w o o d, Biochemical Journal, 37, 79, 1943.

8. TakeruHiguchi, N. C. Hill, G. B. Corcoran, Analytical Chemistry, No 3, 1952.

9. R. B. R a n d a l l, M. B enger and C. M. Groocock, Researches on the Chemistry of Coal, Proceedings of the Royal Society, Series A, Vol. 165, No 992, p. 432, 1938. 